\title{
An Approach to Study the Body Back Discomfort of Economy Class Aircraft Passenger
}

\author{
CheeFai Tan, ${ }^{1,2}$, Wei Chen ${ }^{1}$ and Matthias Rauterberg ${ }^{1}$ \\ ${ }^{1}$ Department of Industrial Design, \\ Eindhoven University of Technology, \\ 5612AZ Eindhoven, the Netherlands \\ ${ }^{2}$ Universiti Teknikal Malaysia Melaka, \\ Melaka, Malaysia
}

\begin{abstract}
The paper describes the questionnaire study that was designed to unfold the relationship between different body back discomfort levels over time. One hundred and four anonymous self administered questionnaires were completed at Schipol International Airport, the Netherlands from October through November 2008. Long haul economy class aircraft passengers are at risk of uncomfortable for long hour sitting and experience significant uncomfortable at different body back parts such as arm, neck and lower leg.
\end{abstract}

KEYWORDS: BODY DISCOMFORT, ECONOMY CLASS AIRCRAFT PASSENGER

\section{INTRODUCTION}

Air travel is becoming increasingly more accessible to people both through the availability of cheap flights and because the airlines are now able to cater for individuals of all ages and disabilities. Health problems may arise due to anxiety 
and unfamiliarity with airport departure procedures prior to flying, whilst during the flight, problems may arise as a result of the food served on board, differences in the environmental conditions inside the cabin (pressure, ventilation, relative humidity, noise and vibration), the risk of cross-infection from fellow passengers, seat position, posture adopted and duration of the flight. These can be further compounded by changes in time zones and meal times, which may continue to affect an individual's health long after arrival at the final destination (Brundrett, 2001). Travel by air, especially long distance, is not a natural activity for human. Many people experience some degree of physiological and psychological discomfort and even stress during flying. Excessive stress may cause passenger to become aggressive, over-reaction, and even endanger the passenger's health (Kalogeropoulos, 1998; World Health Organization, 2007). A number of health problems can affect flying passengers.

Comfort is an attribute that today's passenger demand more and more. The aircraft passenger's comfort depends on different features and the environment during air travel. Seat discomfort is a subjective issue because it is the customer who makes the final determination and customer evaluations are based on their opinions having experienced the seat (Runkle, 1994). The aircraft passenger seat has an important role to play in fulfilling the passenger comfort expectations. The seat is one of the important features of the vehicle and is the place where the passenger spends most of time during air travel. The aviation industry is highly competitive and therefore airlines try to maximize the number of seats (Quigley et al., 2001). Often this results in a very limited amount of seating space for passengers, especially in economy class (Hinninghofen and Enck, 2006).

Long haul economy class aircraft passengers are at risk uncomfortable for long hour sitting and experience significant uncomfortable at different body back parts such as neck and lower leg. Further studies concerning how to best provide comfort to long haul economy class aircraft passenger are needed. This questionnaire study was set out to examine the different body back parts discomfort of economy class aircraft passenger to help prioritize action aimed at discomfort reduction. One hundred and four anonymous self administered surveys were completed at Schipol International Airport, the Netherlands from October through November 2008.

\section{METHODS}

\section{QUESTIONNAIRE DEVELOPMENT}

The questionnaire consisted of three sections: (1) questions about the respondents' travel frequency by aircraft per year, common flight duration and the class; (2) question about their uncomfortable level of each part of their body backside after one hour and five hours flight; (3) question about demographic background.

The questionnaire begins with a short, self-explanatory introduction in which the purpose and background of the survey were explained; it was also emphasizes that data would be treated with confidentiality and analyzed in an anonymous manner. An example on how to answer the question correctly is shown. 
The primary means of investigation is to identify the body discomfort level with regards on time during air travel. This was devised to identify the body part discomfort, to indicate the discomfort level for each defined body part for after one hour and after five hours of flight. In order to identify the body part discomfort level, a body mapping method is used. In this method, the perception of discomfort is referred to a defined part of the body. The subject is asked for the discomfort experiences during flight for each defined body part. The subject is asked to assess the discomfort level using a five point Likert scale. The scales are graded from 'extremely discomfort' to 'normal'. Figure 1 shows the body map and scales for discomfort assessment.

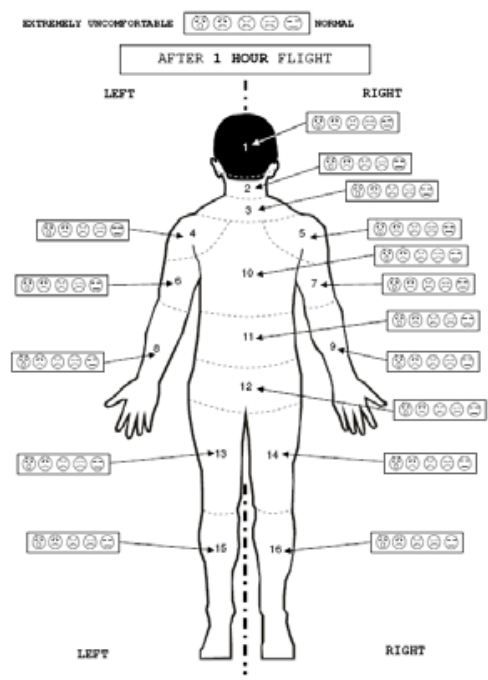

FIGURE 1 Body map and scales for body discomfort evaluation.

\section{QUESTIONNAIRE SAMPLING}

The questionnaire was completed by 104 aircraft passengers who were randomly sampled. The investigator was present on each occasion, during which aircraft passengers were approached and the aims of the investigation were briefly outlined. The questionnaire took between 3-5 min for self-completion.

\section{RESULTS}

50 females and 54 males completed the questionnaire. A wide range of ages was represented (17 to 75 years). The mean BMI of the respondents were $24.09 \mathrm{~kg} / \mathrm{m}^{2}$ and it is generally accepted as being in the 'overweight' category $(\mathrm{M}=24.09$, $\mathrm{SD}=4.93)$. 
We conducted a Factor Analysis on body part discomfort level after one hour flight and after five hours flight, to identify the underlying dimensions of the body part discomfort of aircraft passenger. Scores on the sixteen statements were submitted to principal components factor analysis with Varimax Rotation. A Screeplot indicated that the eigenvalues started to level off after three factors. Thus, a three factor solution yielded the best solution.

\section{BODY DISCOMFORT LEVEL AFTER ONE HOUR FLIGHT}

For 'after 1 hour flight', the three factors explained $72.75 \%$ of the variance in the data. Table 1 provides an overview of the composition of the three factors for body part discomfort after 1 hour flight. The first factor included five items that described the body discomfort at buttock, upper leg (left and right) and lower leg (left and right). This factor appeared to reflect the lower body of the respondent. Therefore, it was labeled as "Lower body". The second factor included four items. All four items described the body part, which are upper arm (left and right) and lower arm (left and right). The second factor was labeled as "Arm". The third factor included seven items, namely, head, neck, shoulder, left shoulder, right shoulder, upper back and lower back. The third factor was labeled as "Upper body".

Table 1 Results of Factor Analysis of Body Part Discomfort after One Hour Flight.

\begin{tabular}{lccc}
\hline & & Factor & \\
\hline & Lower body & Arm & Upper body \\
\hline Right lower leg & .910 & & \\
Right upper leg & .902 & & \\
Left upper leg & .896 & & \\
Left lower leg & .890 & & 405 \\
Buttock & .716 & .902 & \\
Right upper arm & & .880 & \\
Left upper arm & & .763 & \\
Right lower arm & & .739 & \\
Left lower arm & & & .831 \\
Neck & & & .772 \\
Shoulder & & 428 & .683 \\
Lower back & & 568 & .659 \\
Upper back & & 568 & .612 \\
Right shoulder & & .612 \\
Left shoulder & & & .588 \\
Head & & .89 & $.81 \%$ \\
\hline \multicolumn{1}{c}{ Explained variance } & $46.76 \%$ & & $.86 \%$ \\
\hline \multicolumn{1}{c}{ Cronbach’s Alpha } & .95 &
\end{tabular}

Note: Only factor loadings $>0.58$ are selected 


\section{BODY DISCOMFORT LEVEL AFTER FIVE HOURS FLIGHT}

For 'after 5 hours flight', the three factors explained $74.04 \%$ of the variance in the data. Table 2 provides an overview of the composition of the three factors for body part discomfort after five hours flight. There were four items labeled as "Arm" in first factor. The first factor included left lower arm, left upper arm, right lower arm and right upper arm. The second factor included six items that described the body discomfort at neck, shoulder, left shoulder, right shoulder, upper back and lower back. This factor appeared to reflect the upper body of the respondent. The second factor labeled as "Upper body". The third factor included five items, namely, buttock, right lower leg, right upper leg, left lower leg and left upper leg. The third factor was labeled as "Lower body".

Table 2 Results of Factor Analysis of Body Part Discomfort after Five Hours Flight.

\begin{tabular}{lccc}
\hline & \multicolumn{3}{c}{ Factor } \\
\hline & Arm & Upper body & Lower body \\
\hline Left lower arm & .904 & & \\
Left upper arm & .881 & & \\
Right lower arm & .869 & & \\
Right upper arm & .829 & 489 & \\
Head & & .866 & \\
Shoulder & & .843 & \\
Neck & & .800 & \\
Lower back & & .671 & \\
Upper back & 550 & .648 & \\
Left shoulder & 585 & .603 & .904 \\
Right shoulder & & & .879 \\
Right lower leg & & & .838 \\
Left lower leg & & & .805 \\
Right upper leg & & 428 & .593 \\
Left upper leg & & $15.48 \%$ & $11.46 \%$ \\
Buttock & \multicolumn{1}{c}{ Explained variance } & $47.10 \%$ & .89 \\
\hline \multicolumn{1}{c}{ Cronbach's Alpha } & .94 & & .90 \\
\hline
\end{tabular}

Note: Only factor loadings $>0.59$ are selected

Univariate analysis of variance was conducted to find the differences of body discomfort level between after one hour flight and after five hours flight. Figure 2 showed the comparison of body discomfort level for different body part after one hour and after five hours flight. The results showed the body discomfort level after five hours flight was more discomfort than body discomfort level after one hour flight. 


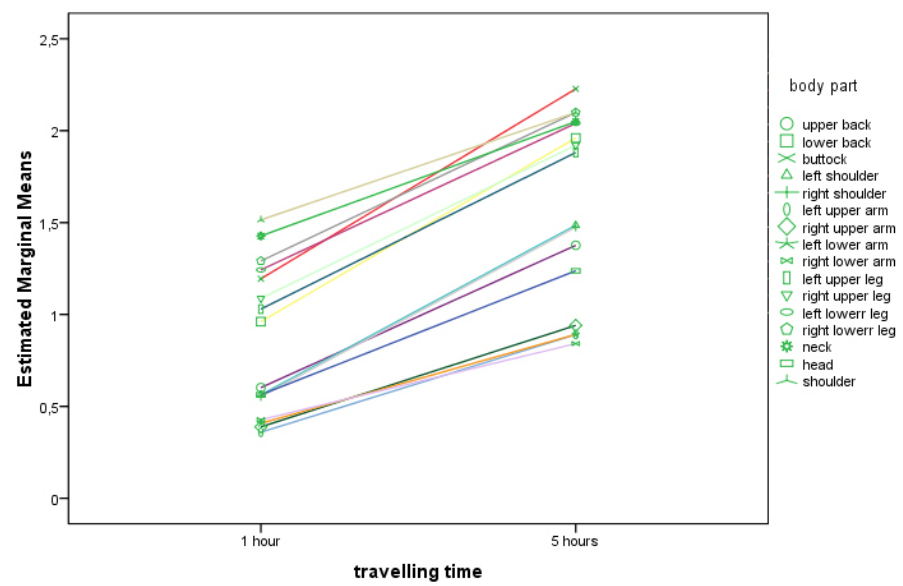

FIGURE 2 Univariate analysis result for different body discomfort level.

\section{DISCUSSION}

With respect to travel duration, passengers who travelled with 6 to 10 hours reported highest body discomfort level. The result showed that longer flight duration was causing higher discomfort at arm section. Male respondents felt higher body discomfort level at lower body section than female respondents. In the other hand, older aircraft passengers felt that their arm was more discomfort after one hour flight. The passengers with higher BMI reported that their lower body section is more discomfort after one hour flight.

Through one-way ANOVA analysis at body discomfort level after five hours flight, the aircraft passengers who travelled 11 times or more in a year have reported highest body discomfort level at upper body section. Subsequently, passengers with longer flight duration perceived higher discomfort level at arm section after five hours flight. The gender of respondents affected the body discomfort level at upper body and lower body section. Female respondents found to be more discomfort than male respondents for after five hours flight. Female respondents reported that they have highest body discomfort level at upper body section. Male respondents reported the lower body section as the most discomfort section. Neck and shoulder showed the similarity of body discomfort level for after one hour and after five hours flight. The body discomfort level for buttock was the highest in rank after five hours flight.

Based on the ranking of the body discomfort level, the main areas of body discomfort after one hour flight were shoulder, neck and right lower leg. Subsequently, the main areas of body discomfort after five hours flight were buttock, shoulder and neck. The body discomfort after five hours flight of buttock and neck were similar to the study by Quigley et al. (2001). The study found that the main areas of complaint during the flight were lower back, buttocks and neck. 
The lower back was ranked after neck for the body discomfort level after five hours flight.

\section{CONCLUSION}

In the present research, we sought to gain more insights into aircraft passenger body discomfort level between after one hour flight and after five hours flight, especially with regards to flight frequency, flight duration, and gender. There are 104 respondents filled up the questionnaire about body discomfort level after one hour and after five hours flight. In line with the survey hypothesis, findings confirmed that aircraft passenger who travelled after five hours are more discomfort than passenger who travelled after one hour. The finding showed that buttock, shoulder and neck were rank as main body discomfort level after five hours flight. Economy class aircraft seat discomfort was associated with flight duration. Interventions aimed at improving the aircraft seat comfort should be prioritized when devising a discomfort reduction strategy for economy class aircraft passengers.

\section{REFERENCES}

Brundrett, G. (2001), "Comfort and health in commercial aircraft: a literature review." The Journal of The Royal Society for the Promotion of Health, 121(1), 29-37.

Kalogeropoulos, S. (1998), Sky rage. Flight Safety Australia, 36-37.

World Health Organization, (2007), "Travel by air: health considerations," http://whqlibdoc.who.int/publications/2005/9241580364_chap2.pdf. Accessed on $3^{\text {rd }}$ March 2007.

Runkle, V.A. (1994), “Benchmarking seat comfort.” SAE Technical Paper, 940217.

Quigley, C., Southall, D., Freer, M., Moody, A. and Porter, M. (2001), Anthropometric study to update minimum aircraft seating standards. EC1270, ICE Ergonomics Ltd., 2001.

Hinninghofen, H. and Enck, P. (2006), "Passenger well-being in airplanes.” Auton Neurosci, 129(1-2), 80-85. 